\title{
Key issues in phage therapy
}

DEF E N CE

Jean-Paul Pirnay, ${ }^{1}$ Maia Merabishvili, ${ }^{1}$ Gilbert Verbeken, ${ }^{1}$ Daniel De Vos, ${ }^{1}$ Patrick Soentjens, ${ }^{2}$ Thomas Rose, ${ }^{2}$ and Serge Jennes ${ }^{2}$

${ }^{1}$ Laboratory for Molecular and Cellular Technology, ${ }^{2}$ Burn Wound Center, Queen Astrid military hospital, Brussels, Belgium

Phage therapy is increasingly highlighted as a promising 'new' treatment option for bacterial infections. Countries that had less access to antibiotics during the cold war, such as Georgia, have years of data on the efficacy of phage therapy.

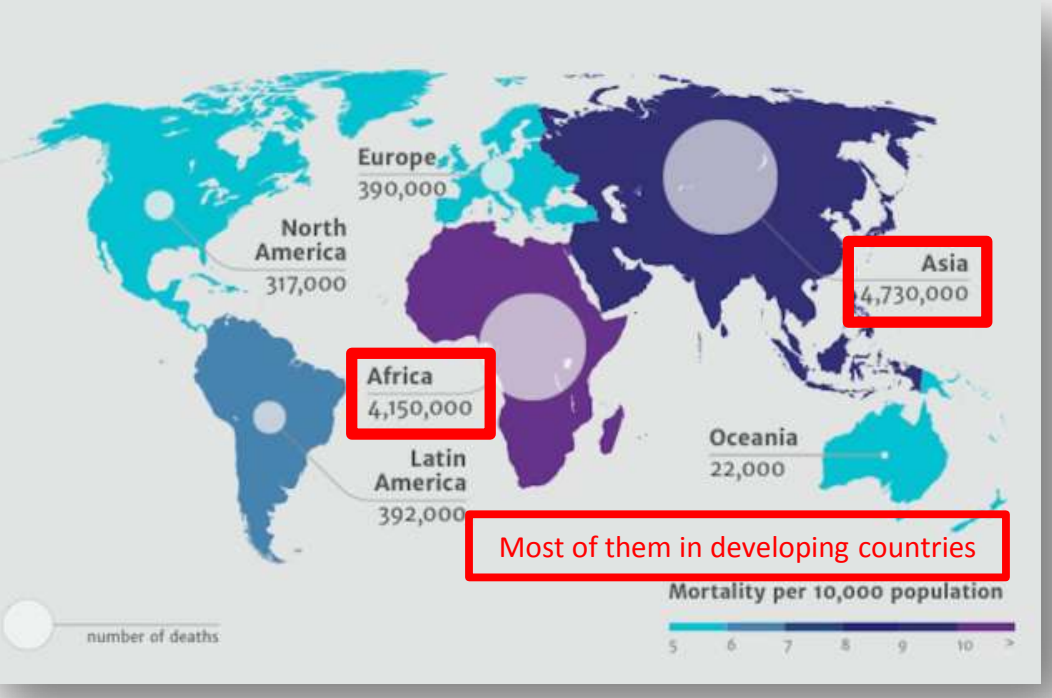

1. Perception

a. Viruses as enemies of life

b. Soviet Union research as 'academically inferior'

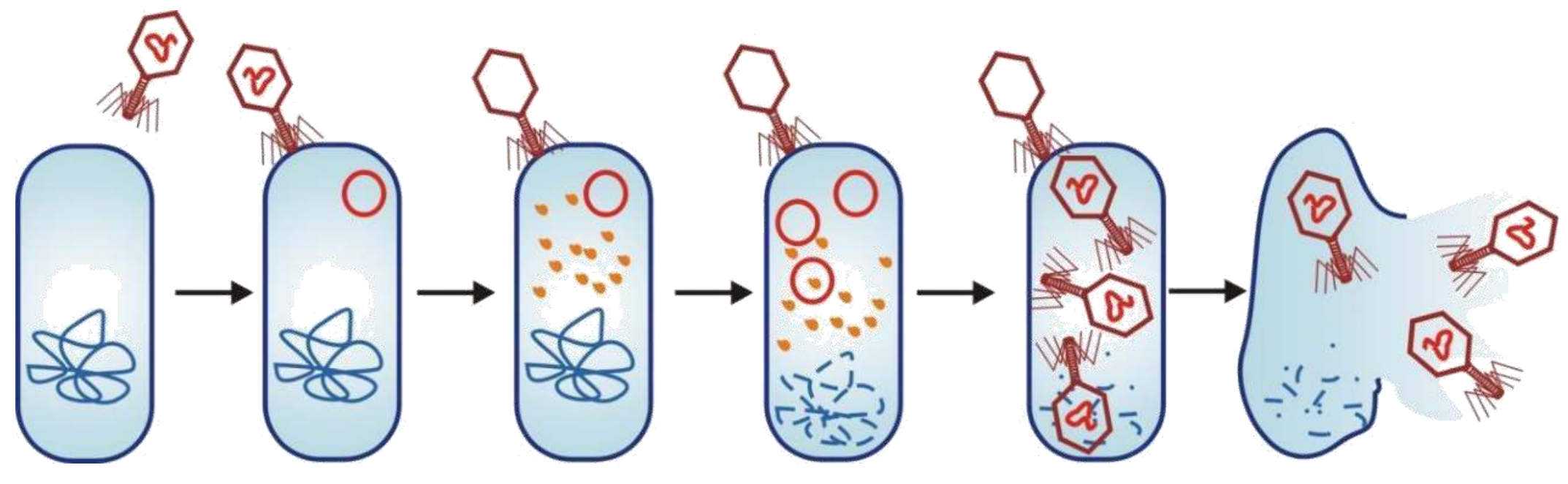

\section{Phage specificity}

3. Bacterial phage resistance evolution

\section{4. $\quad$ Phage $=$ Medicinal Product (drug) \\ $\rightarrow$ Pharmaceutical Pathways \\ a. Non flexibel (Production (GMP) \& Marketing) \\ b. Conventional clinical trials \\ c. Time-consuming and expensive \\ d. Weak Intellectual Property Protection}

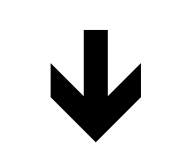

No phages on EU and US markets

Sporadic applications: Art. 37 Declaration of Helsinki

\section{$\downarrow$}

Magistral (compounding) phage preparations

- Flexibel (sustainable) approach

- Relatively inexpensive
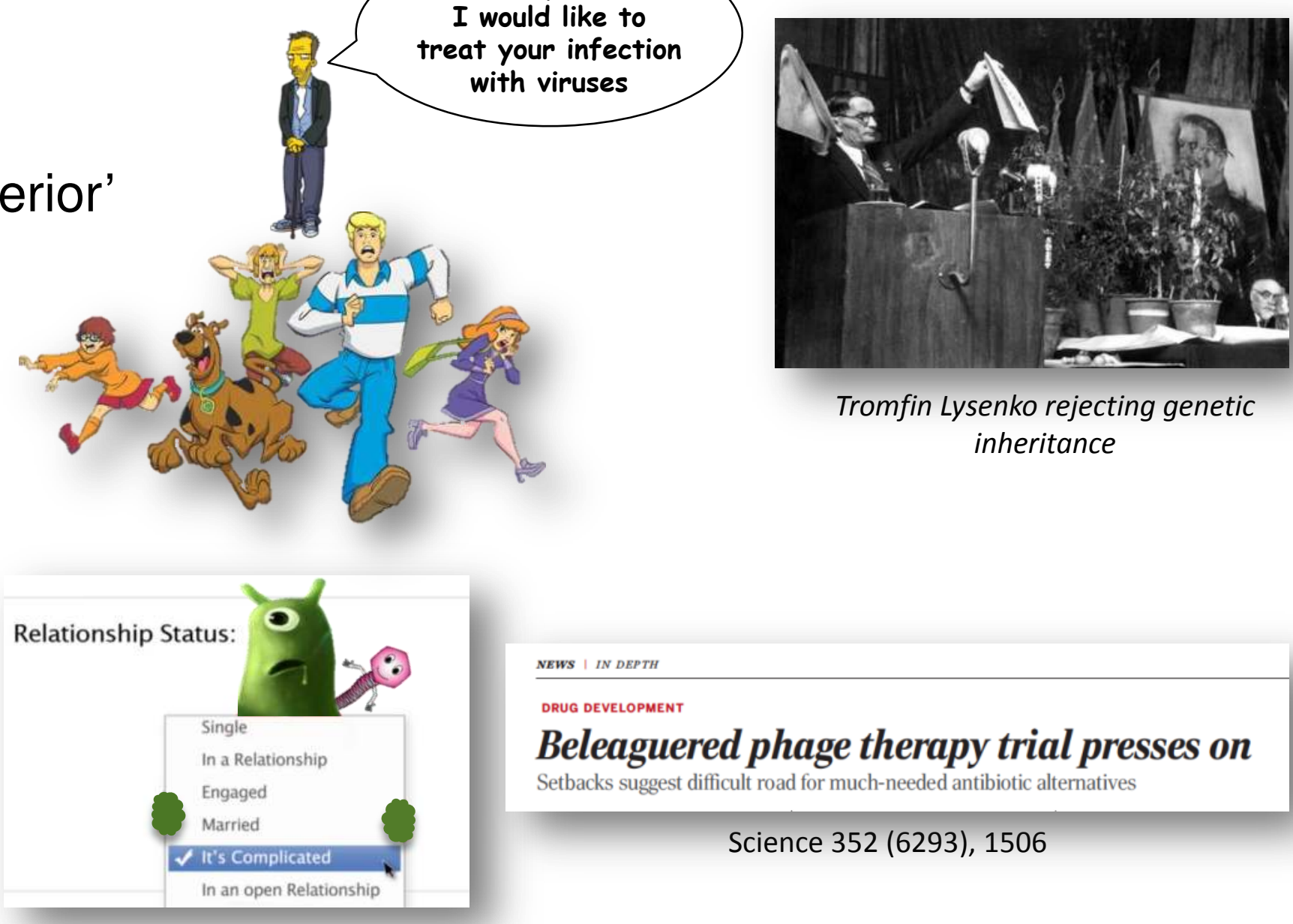

Beleaguered phage therapy trial presses on Science 352 (6293), 1506
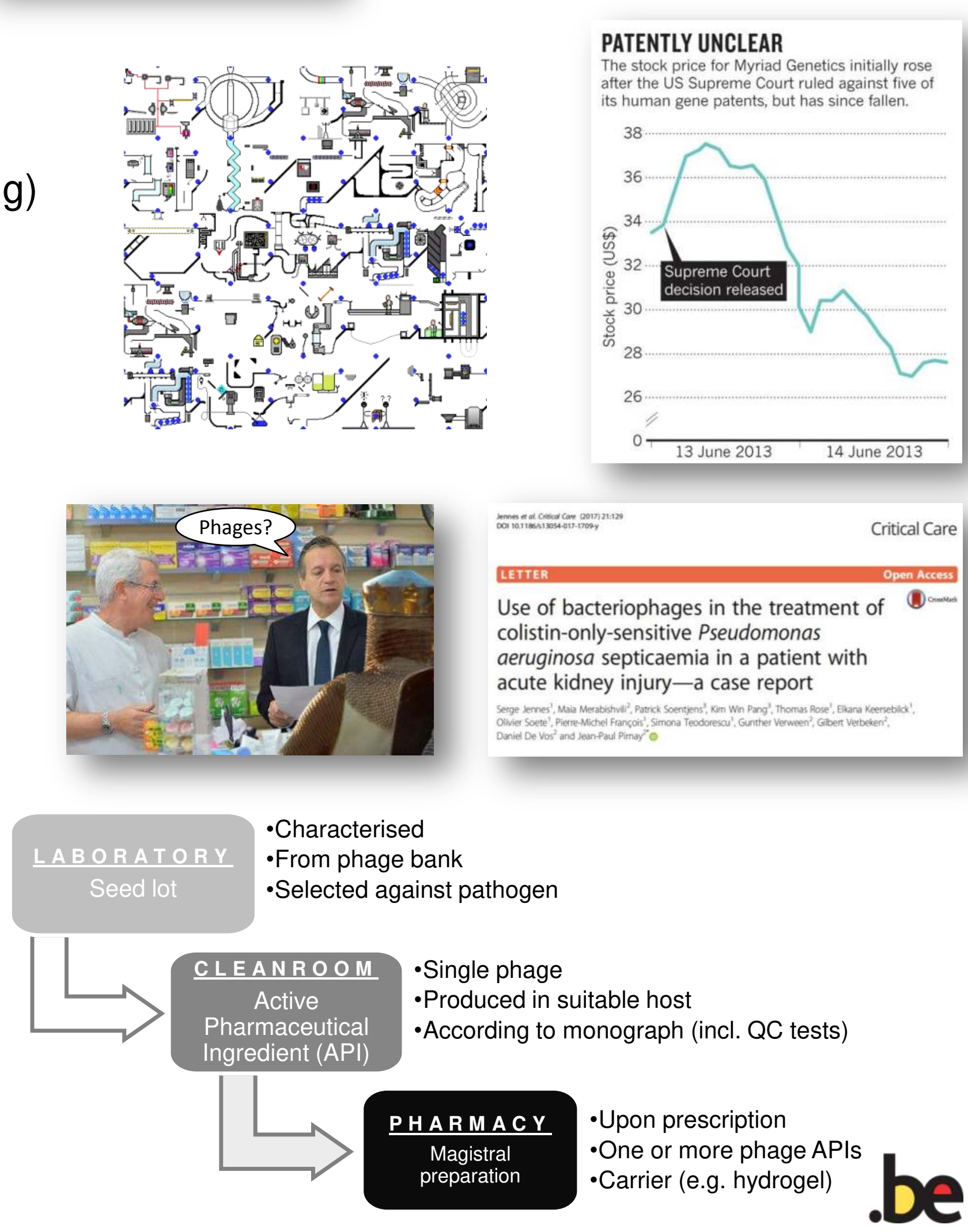